\title{
Neurogenic bladder revealing a pernicious anemia: One case report and literature review
}

\author{
Omar Riyach", Mustapha Ahsaini*, Mohammed Fadl Tazi, Jalal Eddine El Ammari, \\ Mohammed Jamal El Fassi, Abdelhak Khallouk, Moulay Hassan Farih
}

Department of urology, University Hospital Center Hassan II-FES, MOROCCO

Email address:

riyach2@hotmail.com (O. Riyach)

To cite this article:

Omar Riyach, Mustapha Ahsaini, Mohammed Fadl Tazi, Jalal Eddine El Ammari, Mohammed Jamal El Fassi, Abdelhak Khallouk, Moulay Hassan Farih. Neurogenic Bladder Revealing a Pernicious Anemia: One Case Report and Literature Review. Clinical Medicine Research. Vol. 3, No. 3, 2014, pp. 61-64. doi: 10.11648/j.cmr.20140303.12

\begin{abstract}
Background: Neurogenic or neuropathic bladder is defined as any defective functioning of the bladder caused by impaired innervations. Pernicious anemia is a rare cause of neurogenic bladder and it is often accompanied by other neurological manifestations. The standard treatment is based on parenteral vitamin administration. We report a unique case of pernicious anemia revealed by a neurogenic bladder succefully managed by vitamin B12 administration. Case presentation: A 45-year-old man presented with lower urinary tract symptoms (LUTS) with urine retentions. The patient was an important postvoid residual volume. The uroflowmetry result of the patient was low. Cystoscopy reveals a normal urethra, prostatic fossa, and bladder. Urodynamic testing demonstrated a failure voiding bladder. The diagnostic of pernicious anemia was suspected in laboratory exams which have showed megaloblastic anemia and Serum antibodies to gastric parietal cells, the diagnostic was confirmed by gastric biopsy. The patient was traited by oral administration of vitamin B12. At his 6 months follow-up, clinical symptoms had improved, and there was no significant postvoid residual (PVR). Conclusion: The vesicosphincteriens disorders in pernicious anemia are very little detail in the literature .our case is to our knowledge the first to have urinary voiding dysfunction as the only symptom of pernicious anemia with spectacular improvement after vitamin B12 administration.
\end{abstract}

Keywords: Pernicious Anemia, Vesicosphincteriens Disorders, Vitamin B12, Postvoid Residual (PVR)

\section{Introduction}

Neurogenic lower urinary tract dysfunction or neurogenic bladder (NGB) dysfunction may be caused by various diseases and events affecting the nervous system controlling the lower urinary tract [1]. It occurs equally in men and women [2]. Pernicious anemia is a rare cause of myelopathy linked to a deficiency of vitamin B12. The urinary disturbances are part of the neurological signs. But it has never seen that a neurogenic bladder was the first and the only neurological sign of this pathology. We report one case of pernicious anemia revealed by neurogenic bladder with complete urinary function recovery after treatment with vitamin B 12, and we analyzed the clinical data and reviewed the relevant literature published.

\section{Case Presentation}

A 45-year-old man presented with mild to moderate lower urinary tract symptoms (LUTS) of one year duration with frequent history of catheterizations for urine retentions. $\mathrm{He}$ has no past history of infection, urethral stricture disease, or benign prostatic hypertrophy. The patient was comfortable and had no sensation of needing to void. The physical examination reveals no sensitive or motor deficits. A catheter was placed but the patient was unable to void after the catheter was removed. A postvoid residual volume obtained by noninvasive bladder ultrasonography reveals $1000 \mathrm{~mL}$ (figure 1).

Retrograde and voiding urethro-cystography was normal (figure 2). The uroflowmetry result of the patient was Qmax: 6, $3 \mathrm{~mL} / \mathrm{sec}$. Cystoscopy reveals no obstructive lesions and a normal-appearing urethra, prostatic fossa, and bladder. Urodynamic testing demonstrated a normal capacity, compliant bladder 


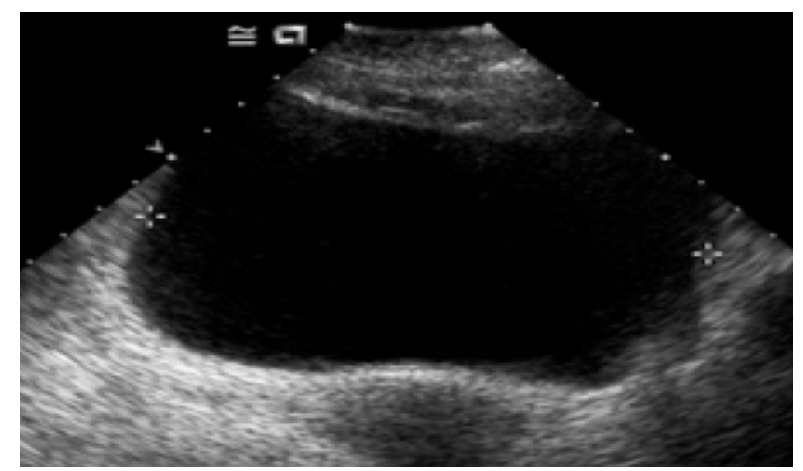

Figure 1. A postvoid residual volume obtained by noninvasive bladder ultrasonography reveals $1000 \mathrm{~mL}$.

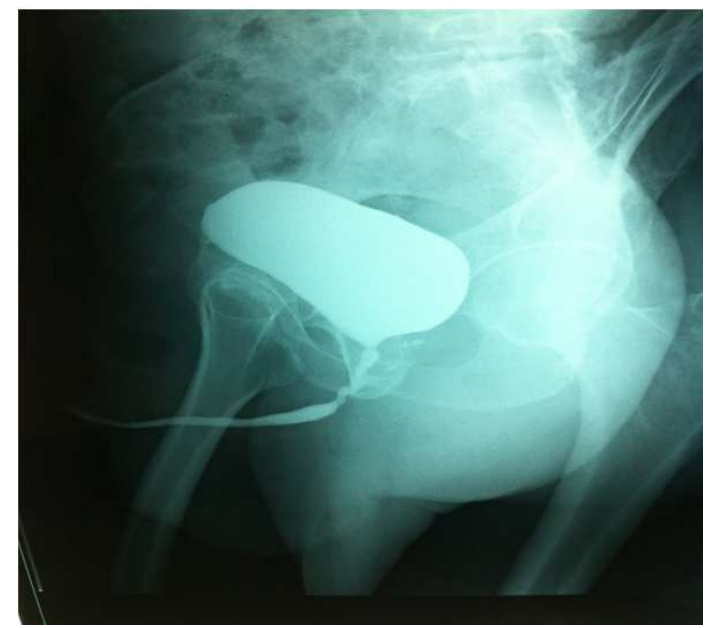

Figure 2. Retrograde and voiding urethro-cystography was normal.

The patient was unable to sense filling at any volume and is also unable to generate any voiding contraction (figure 3 ). Examination of the peripheral blood showed the red blood cell count to be 2, 2 million, WBC 280o, hemoglobin 7.9 Gm. per 300 cc., hematocrit 28 per cent, and average cell volume $12.7 \mathrm{Cu}$. microns. In the stained blood films the erythrocytes varied greatly in size and in shape, reticulocytes were slightly less than a per cent, and the percentage of neutrophils was reduced with many of them having multilobed nuclei. Laboratory exams showed also revealed Serum antibodies to gastric parietal cells in the peripheral blood examination, the diagnosis of pernicious anemia was selected by highlighting a chronic gastritis fundic atrophy and intrinsic factor antibodies. The patient was treated by vitamin B12 orally at $500 \mathrm{mg} /$ day and received a folic acid. The evolution was marked by a disappearance under treatment of urinary disturbances, macrocytosis correction and normalization of vitamin B12. At 6 months follow-up, clinical symptoms had improved, and postvoid residual (PVR) was $75 \mathrm{~mL}$.

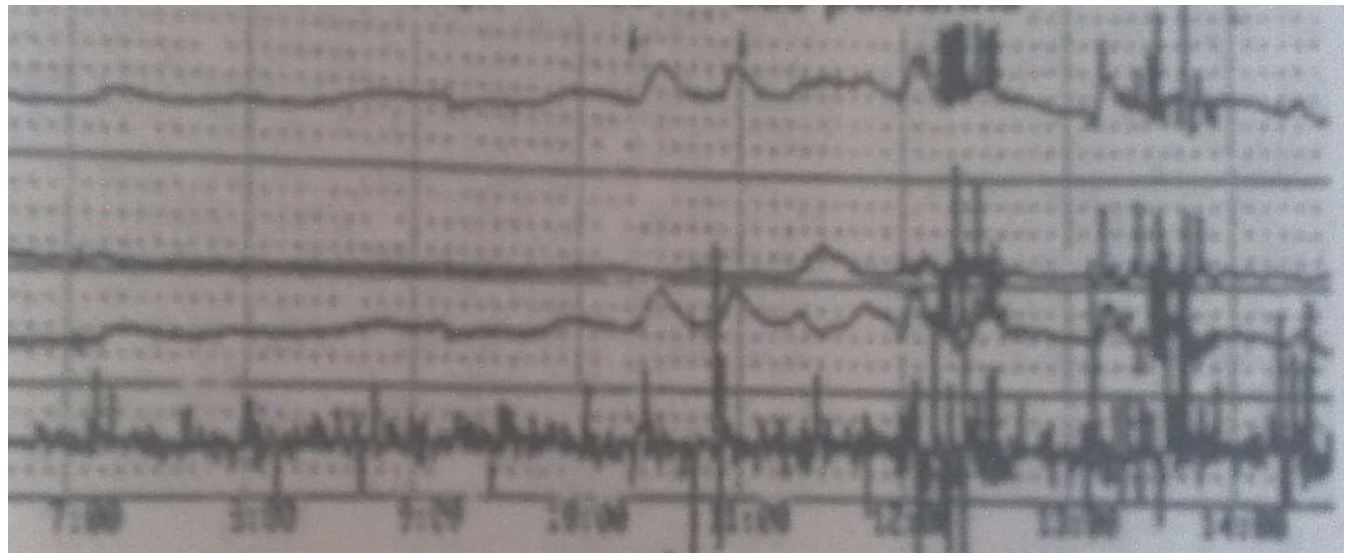

Figure 3. Urodynamic testing demonstrated the unabilty to generate any voiding contraction. 


\section{Discussion}

Pernicious anemia (PA) (also known as Biermer's disease [3] and Addisonian anemia [4]) is a macrocytic anemia due to vitamin B12 (cobalamin) deficiency, which, in turn, is the result of deficiency of intrinsic factor [5]. The deficiency of intrinsic factor is a consequence of the presence of atrophic body gastritis $(\mathrm{ABG})$, which results in the destruction of the oxyntic mucosa, and thus, the loss of parietal cells, which normally produce chlorhydric acid as well as intrinsic factor [6]. The term PA is sometimes used as synonym for cobalamin deficiency or for macrocytic anemia, but to avoid ambiguity, PA should be reserved for conditions that result from impaired secretion of intrinsic factor and atrophy of oxyntic mucosa [7]. $\mathrm{PA}$ is considered an autoimmune disorder due to the frequent presence of gastric autoantibodies directed against intrinsic factor, as well as against parietal cells. PA is often considered a synonym of autoimmune gastritis, because PA is thought to be the end stage of an autoimmune process that results in severe damage of the oxyntic gastric mucosa [8]. Recent experimental and clinical data strongly suggest an involvement of long-standing Helicobacter pylori (H pylori) infection in the pathogenesis of $\mathrm{ABG}$ and $\mathrm{PA}$, but it is still under debate whether PA may be included among the long-term consequences of $\mathrm{H}$ pylori gastritis [9]. Disturbed genitourinary function is a well known late result of neurologic disease in patients with pernicious anemia but the details of the functional deficit as related to the general neurologic condition as well as the eventual prognosis have received very little study. The earliest symptom to appear in male patients is usually impotence. Hesitancy, weakness of the urinary stream, and finally urinary retention, dribbling, or overflow incontinence develop later. Exceptionally our patient presented a neurogenic bladder as the first and the only symptom of pernicious anemia. Neurologic examination in these patients invariably shows cutaneous sensory impairment in the lower legs and diminished or absent vibratory sense to the level of the iliac crests. Evidence of lateral column disease may or may not be present. Cystometric examination usually discloses the presence of an atonic bladder paralysis with impaired sense of bladder filling, very low intravesical pressure, increased bladder capacity and variable amounts of residual urine. Most observers agree that bladder neck and sphincter symptoms may disappear with treatment of the pernicious anemia $[10,11$, 12]. As we have shown in our case the patient regained normal bladder function as regards both symptoms and cystometric findings after a few of liver therapy by vitamin B12. The prognosis when the paralysis is of longer duration is undoubtedly less favorable. Urologic measures designed to avoid mechanical damage to the detrusor muscle, urinary tract infection, and bladder neck obstructions are of prime importance during the period of recovery. The clinical management of patients with PA is based on the treatment of cobalamin deficiency which is able to correct the anemia, whereas the neurological complications may be corrected only if the replacement treatment is given soon after their onset.
The therapeutic recommendations for PA with regard to dosage and administration of vitamin B12 substitution treatment are divergent [13]. According to our protocol, a higher dosage of cobalamin is used orally at $500 \mathrm{mg} /$ day in addition of folic acid. PA is an often silent and underdiagnosed autoimmune disease, because its onset and progression are very slow, According to the literature the urinary disorders occur at an advanced stage of the disease and respond to treatment with vitamin B 12. For the first time in the English literature, a case of pernicious anemia diagnosed by neurogenic bladder as the only manifestation of this pathology is presented. Our findings indicate that treatment of urinary retention associated with pernicious anemia is managed by intermittent catheterization with oral vitamin B12 administration, with complete urinary function recovery.

\section{Conclusion}

Neurogenic bladder is one of disturbed neurologic function that occurs in pernicious anemia, but it has never been reported that this symptom is the only manifestation of this disease. Our case is the first of its kind to expose this clinic particularity, and still the best example for a reversible neurogenic bladder with complete recovery of urinary function after medical treatment.

\section{Consent}

Written informed consent was obtained from the patient for publication of this manuscript and accompanying images. A copy of the written consent is available for review by the Editor-in-Chief of this journal.

\section{Competing Interests}

Authors declare that they have no competing interests.

\section{Author's Contribution}

OR, MA: the principal authors, major contributions in writing the manuscript.

MFT, JE, MJE, AK and MHF: analyzed and interpreted the patient data and the reviews of the literature.

All authors read and approved the final manuscript.

\section{References}

[1] Stedman's online medical dictionary. Lippincottt Williams \& Wilkins. http://www.stedmans.com. Accessed July 23, 2007.

[2] Curtis LA, Dolan TS, Cespedes RD. Acute urinary retention and urinary incontinence. Emerg Med Clin North Am. 2001;19(3):591-619.

[3] Zittoun J. [Biermer's disease] Rev Prat 2001; 51: 1542-1546 
[4] Meecham J, Jones EW. Addison's disease and Addisonian anaemia. Lancet 1967; 1: 535-538

[5] Wintrobe MM, Lee GR, Boggs DR, Bithell TC, Foerster J,Athens JW, Lukens JN. Megaloblastic and nonmegaloblastic macrocytic anemias. In: Wintrobe MM, Lee GR, Boggs DR, Bithell TC, Foerster J, Athens JW, Lukens $J \mathrm{~N}$, editors. Clinical hematology. 8th ed. Philadelphia: Lea \& Febiger, 1981: 559-604

[6] Lee EL, Feldman M. Gastritis and other gastropathies. In: Feldman M, Friedman LS, Sleisenger MH, editors. Sleisenger \& Fordtran's gastrointestinal and liver disease: pathophysiology, diagnosis, management. 7th ed. Philadelphia: Saunders, 2002: 810-827

[7] Babior BM. Erythrocyte disorders: Anemias related to disturbance of DNA synthesis (megaloblastic anemias). In: Williams JW, Beutler E, Erslev AJ, Lichtman MA, editors. Hematology. 4th ed. New York: McGraw-Hill, 1998: 453481

[8] Toh BH, Gleeson PA, Whittingham S, van Driel IR.
Autoimmune gastritis and pernicious anemia. In: Rose NR, Mackay IR, editors. The autoimmune diseases. 3rd ed. St. Louis, MO: Academic Press, 1998: 459-476

[9] D'Elios MM, Appelmelk BJ, Amedei A, Bergman MP, Del Prete G. Gastric autoimmunity: the role of Helicobacter pylori and molecular mimicry. Trends Mol Med 2004; 10: 316-323

[10] FARQUHARSON, R. F., AND GRAHAM, D.: Liver therapy in the treatment of subacute combined degeneration of the cord. Canadian M. A. J. 23: 137, 1930.

[11] HYLAND, H. H., AND FARQUHARSON, R. F.: Subacute combined degeneration of the spinal cord in pernicious anemia. Arch. Neurol. \& Psychiat. 36: ii66, 1936.

[12] UNGLEY, C. C., AND SUZMAN, M. M.: Subacute combined degeneration of the cord: symptomatology and effects of liver therapy. Brain 52.' 2.71, 192.9.

[13] Hvas AM, Nexo E. Diagnosis and treatment of vitamin B12 deficiency--an update. Haematologica 2006; 91: 1506-1512 